\title{
Asthma: prevalence and cost of illness
}

\author{
S. Stock, M. Redaelli, M. Luengen, G. Wendland, D. Civello and K.W. Lauterbach
}

ABSTRACT: The purpose of this study was to estimate the prevalence and cost of illness of asthma in Germany by retrospectively analysing routine health insurance data.

This analysis investigated claims data from all insured persons of six large sickness funds. Insurants with asthma were identified via the International Classification of Diseases (ninth revision) diagnosis and the Anatomical Therapeutic Chemical Classification System Code for regular medication prescriptions. Costs for hospital care, medication and sick benefit were taken from claims data. Costs for rehabilitation, premature death and early retirement were estimated using the human capital approach and data from national statistics.

Prevalence of asthma in the German statutory health insurance was $6.34 \%$. Total costs for asthma, including direct and indirect costs, were calculated at $€ 2.74$ billion during 1999.

The prevalence of asthma in the German statutory health insurance has previously been estimated to be $4-6 \%$. The results of this large study show the prevalence of asthma in the German social insurance system to be $\sim 6 \%$. The study also indicates that there is room for substantial savings in the German social insurance system, with indirect costs amounting to $\mathbf{7 4 . 8 \%}$ of total costs and payment of sick benefits through the sickness funds amounting to $58.3 \%$ of indirect costs. These costs may be reduced with better asthma control in patients.

KEYWORDS: Asthma, cost, Germany, health insurance, prevalence

A sthma is a common chronic disease, which has been reported to have an increasing prevalence and morbidity in western countries with large regional variations, as seen in the European Community Respiratory Health Survey (ECRHS) and the International Study on Asthma and Allergy in children (ISSAC) [1-5]. In early childhood asthma is the single most prevalent chronic disorder and studies have found consistently higher prevalence rates in Australia, New Zealand, Greece, Wales and the USA [6-11]. Estimates for prevalence in Germany range $3-5 \%$ in adults and $\sim 10 \%$ in children [10, 12, 13]. Genetic and environmental factors both play a considerable part in the manifestation of the disease. The role of domestic and environmental factors in developing the disease is not completely clarified. Changes in medical practice, diagnostic labeling and public awareness are also thought to have partly influenced these trends but especially in children the increase is suggested to be real [14]. Yet, regardless of the reasons, morbidity, mortality and the economic burden of asthma in Germany remain high. KONIETZKO and FABEL [10] estimate that 75\% of all patients have mild symptoms that can be easily controlled in outpatient care. However, of these only $\sim 36 \%$ participated in a structured asthma education and only $23 \%$ received an evidence-based treatment regimen. To explain this fact, besides the change in diagnostic procedures and the rising prevalence and severity of the disease, quality deficits in the care of asthma patients and great regional variations in therapy are increasingly cited [15-21].

The aim of this study was to investigate the prevalence of asthma and to provide an estimate of the cost burden in Germany. To the authors' best knowledge this study involves the single largest database of any prevalence and cost studies of asthma in Germany.

\section{RESEARCH DESIGN AND METHODS \\ Data material}

As there is no national registry this study estimates the direct and indirect medical costs and prevalence of asthma in Germany by analysing medical claims data augmented by data from the federal office of statistics (Statistisches Bundesamt) and the association of German pension funds [22, 23]. For reasons of data extraction capability this study involved six large sickness funds including those in the former East and West Germany. Data of these funds were completely analysed and were standardised according to age and sex, with deviation at $<5 \%$. Patient data was anonymous but patient-related identification allowed the tracing of patient-related data sets. To achieve internal validation of the patient-related data sets
AFFILIATIONS

Institute of Health Economics and Clinical Epidemiology of the University of Cologne, Cologne, Germany.

CORRESPONDENCE

S. Stock

Institute of Health Economics and Clinical Epidemiology of the University of Cologne Gleueler Str. 176-178 50935 Cologne Germany Fax: 492214786675 E-mail: Stephanie.Stock@medizin. uni-koeln.de

Received:

October 172003

Accepted after revision:

August 202004
European Respiratory Journal Print ISSN 0903-1936 Online ISSN 1399-3003 
medication data was aligned with International Classification System (ICD) diagnosis from hospital stays and medication prescription was traced over all four quarters of the base year. Plausibility checks found a $<1 \%$ error rate in the internal validity of the data. Errors were mainly related to missing age, in which case insurants were dismissed from the evaluation. Analysed claims data cover hospital costs, medication spending and sick benefits. Aggregated data from national data sources were used to estimate the costs for rehabilitation and lost productivity due to premature death and early retirement. The human capital approach was taken to calculate lost productivity. This assesses the loss of remaining life time productivity by multiplying the lost years of productivity with average income [24].

\section{Estimation of prevalence and cost in the German statutory health insurance}

Estimation of prevalence

For the estimation of prevalence, aggregated days of insurance for insured persons with asthma were brought into proportion with aggregated days of insurance for all insurants. This procedure was used for computing convenience and it approximates asthma prevalence by the quotient of insurance periods and not by actual insurants. It may lead to distortion if the average insurance periods of patients with a chronic disease deviate distinctly from the insurance periods of insurants without asthma. Deviation of this method was judged to be minimal and found to be $<1 \%(0.53 \%)$ by calculating the prevalence from the percentage of individual insurants with asthma from all insurants of the same data.

\section{Estimation of direct costs}

Categories of expenditure for direct costs were inpatient care (hospital costs), outpatient care and inpatient rehabilitation. In the hospital sector patients with asthma as a leading or primary discharge diagnosis were identified using ICD-9 Code 493. Hospital costs for these patients were obtained from claims data. To extrapolate the hospital costs to the whole statutory health insurance (Gesetzliche Krankenversicherung $(\mathrm{GKV})$ ) age and sex stratified data of hospital discharge diagnosis in 1999 using asthma as the primary diagnosis were obtained from the Federal Office for Statistics [22]. To calculate the total costs the number of patients discharged with asthma as a primary diagnosis in each age and sex-stratified group from the Federal Office of Statistics were then multiplied with the age and sex-specific average hospital costs of the identified asthma patients of the study population. Average costs of all hospital stays were taken as hospital stays with asthma as minor diagnosis could not be considered and the amount of asthma-related costs of hospital stays with asthma as a minor diagnosis cannot be accounted for due to the data processing in the GKV. At the same time, total costs reflect true costs more accurately if the costs of asthma-patients are to be compared with costs of insurants without asthma. To adjust for private insured patients in the national statistics, the current authors assumed the prevalence of asthma in private insured patients to be $\sim 5 \%$ (Deutsche Krankenversicherungs AG, personal communication).

Outpatient care was estimated based on medication prescription. Patients were identified using Anatomical Therapeutic
Chemical Classification System (ATC) Codes and the annual costs for all drugs prescribed were obtained. These costs were stratified according to age and sex and extrapolated to the GKV. The total costs of all asthma medication in the GKV was obtained by multiplying the number of sold asthma medication containers obtained from the statistics of the pharmaceutical companies in Germany with the pharmacy price of each container. The fraction of medication costs due to asthma was obtained by setting the total cost of medication in proportion to the asthma-related costs of medication.

The cost of physician outpatient care could not be considered in this study as sickness funds in Germany do not have access to the data. This is because the actual cost of physician visits is not of interest to sickness funds as they pay a fixed per capita premium for each patient regardless of morbidity, actual costs or utilisation of healthcare. In a GKV perspective outpatient physician care of asthma will be described adequately by using medication cost. In other studies however, physician costs amount to $\sim 22 \%$ of the direct costs of asthma [25]. The current study therefore underestimates the costs of asthma from a societal perspective.

To estimate costs for inpatient rehabilitation the current authors used the cases of inpatient rehabilitation for ICD-9 Code 493 differentiated according to age and sex from the statistics of the pension funds association to estimate average costs.

\section{Estimation of indirect costs}

Categories for the estimation of indirect costs considered were sick benefit, early retirement and premature death. The human capital approach and the average gross income to esteem productivity loss due to premature death and early retirement was used. The costs of sick benefit pay were elicited by identifying patients with the ICD-9 diagnosis 493 who received sick benefit payment in 1999. Since all patients who are entitled to sick benefit payment automatically receive it no distortion is to be expected using this approach. The actual amount of sick benefit payment paid to the studied population in the year of 1999 was identified and extrapolated to the GKV by using age and sex-stratified groups.

Productivity loss due to early retirement and premature death was estimated using national data featuring all cases of early retirement and premature death broken down according to ICD-9 in age and sex groups. Lost productivity was calculated for males and females separately using lifetime working spans from 20 to 62 yrs for females and 20 to 65 yrs for males. To establish the total costs of the lost years of productivity due to premature death and early retirement the total number of lost years of productivity was multiplied with the average gross national income per working employee. To calculate the cost of lost productivity for premature deaths the number of deaths for working age insurants according to age, sex and ICD code of the national statistics was used. Working age was defined as above and total cost calculated as outlined.

\section{Identification of insurants with tracers}

The ATC-Code of the World Health Organisation including the extension to the German market and the ICD-9-code (Code 493 for asthma) were used as tracers to identify patients with asthma. In this study in concordance with guideline 
recommendations inhaled selective $\beta_{2}$ agonists (RO3AC) and corticosteroids (RO3BA) were used to identify patients with asthma. Inhaled $\beta$-mimetics were a significant, though weak marker for asthma patients in a study of eight general practices in Germany [26]. Other agents, such as antiallergics and combinations were not considered, although combinations of cromoglycate were specific for asthma in the same study. However, regional variations were considered to be too large. Systemic corticosteroids were not considered as they are known to identify patients with chronic obstructive pulmonary disease (COPD). The same holds true for inhaled corticosteroids in the study of HimMEL et al. [26]. However, inhaled steroids were included, since they are guideline recommended drugs of choice for asthma and prescribing behaviour might have changed since the study of Himmel et al. [26].

Identification via ICD-9 Code can be judged fairly valid. A study of 253 hospitals in Germany showed coding errors $>5 \%$ in internal medicine and neurology in only $7.5 \%$ of the cases [27]. Identification via ATC-code can feature the above mentioned distortions. However, in the identification process diagnosis and medication were matched for all patients, with hospital diagnosis and patients identified via medication with a diagnosis of COPD excluded to minimise distortion.

\section{RESULTS}

\section{Prevalence of identified patients}

The tracer procedure used shows a total prevalence of asthma of $6.34 \%$ in the analysed population. Figure 1 illustrates the prevalence according to sex and age categories.

The highest peak of the curve lies in infancy and early childhood, with $25 \%$ for males and $\sim 17 \%$ for females. After the age of 4 yrs a steady decline in prevalence can be seen. Males have a higher prevalence in childhood and later in life from aged 68 yrs onwards. Females have a higher prevalence than males from aged $\sim 17-62$ yrs. For both sexes prevalence rates at aged 16-62 yrs are 3-7\%. From aged 62 yrs onwards a rise in prevalence in both sexes can be observed, with the male prevalence exceeding female prevalence. Overall prevalence in childhood and young adults (aged $0-19 \mathrm{yrs}$ ) is $11.8 \%$ for males and $9.2 \%$ for females.

\section{Direct costs}

The Federal Office for Statistics accounts for 26,039 male and 26,753 female patients that had a discharge diagnosis of asthma in 1999. Altogether, 52,794 patients were discharged with the leading diagnosis of asthma (table 1).

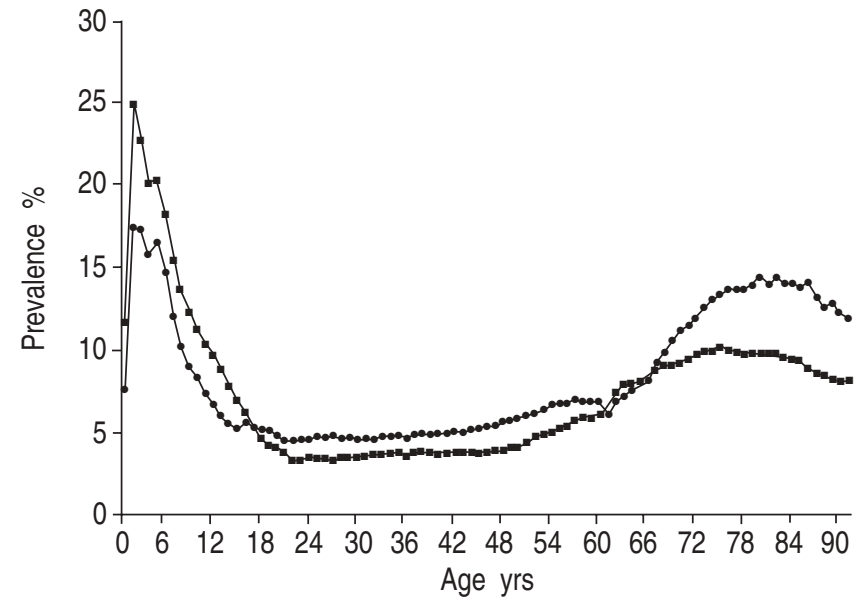

FIGURE 1. Asthma prevalence according to age and sex.

male;

female

Age and sex-specific hospital costs ranged from $€ 564$ in the age group $0-5$ yrs to $€ 2,800$ in the age group of $\geqslant 75$ yrs (fig. 2).

The resulting overall costs of hospital treatment for asthma amounted to $€ 48.2$ million (fig. 3).

In 1999 there were 4,450 cases of rehabilitation of males and 5,543 cases of female patients split according to age and sex, with a total of 9,993 patients with an estimated average of $€ 250$ per day for each [23]. Average length of asthma rehabilitation was considered to be $\sim 25$ days per case. Total cost was estimated by multiplying average costs per case with the number of patients that underwent inpatient rehabilitation, which amounted to $€ 62.5$ million.

Total cost of drug prescription was split up into total cost for asthma medication and total cost of all prescribed medication. Total cost of medication prescribed for patients with asthma was taken from the medical claims of identified insurants. This amounted to $€ 6,411$ million. The total amount of units of asthma medication sold in 1999 were 28.7 units (Intercontinental Marketing Services (Health), Frankfurt, Germany, 2003, personal communication). The amount of units sold multiplied with the pharmacy price of each unit amounted to $€ 579.7$ million of asthma-specific mediation costs in 1999.

Compared to the overall medication costs of patients with asthma the asthma-specific costs of prescription amount to

TABLE 1 Asthma as discharge diagnosis for hospital stays in 1999

\begin{tabular}{|c|c|c|c|c|c|c|c|c|c|c|c|}
\hline & \multirow[t]{2}{*}{ Total } & \multicolumn{10}{|c|}{ Age yrs } \\
\hline & & $0-1$ & $1-5$ & $5-15$ & $15-25$ & $25-35$ & $35-45$ & $45-55$ & $55-65$ & $65-75$ & $>75$ \\
\hline Total & 52794 & 3625 & 4988 & 8713 & 3981 & 3548 & 4306 & 4530 & 6631 & 6804 & 5667 \\
\hline Male & 26039 & 2401 & 3266 & 5482 & 1470 & 1450 & 1659 & 1757 & 3142 & 3299 & 2113 \\
\hline Female & 26753 & 1224 & 1722 & 3231 & 2511 & 2097 & 2647 & 2773 & 3488 & 3505 & 3554 \\
\hline
\end{tabular}

Modified according to Statistisches Bundesamt, 2000 [22]. 


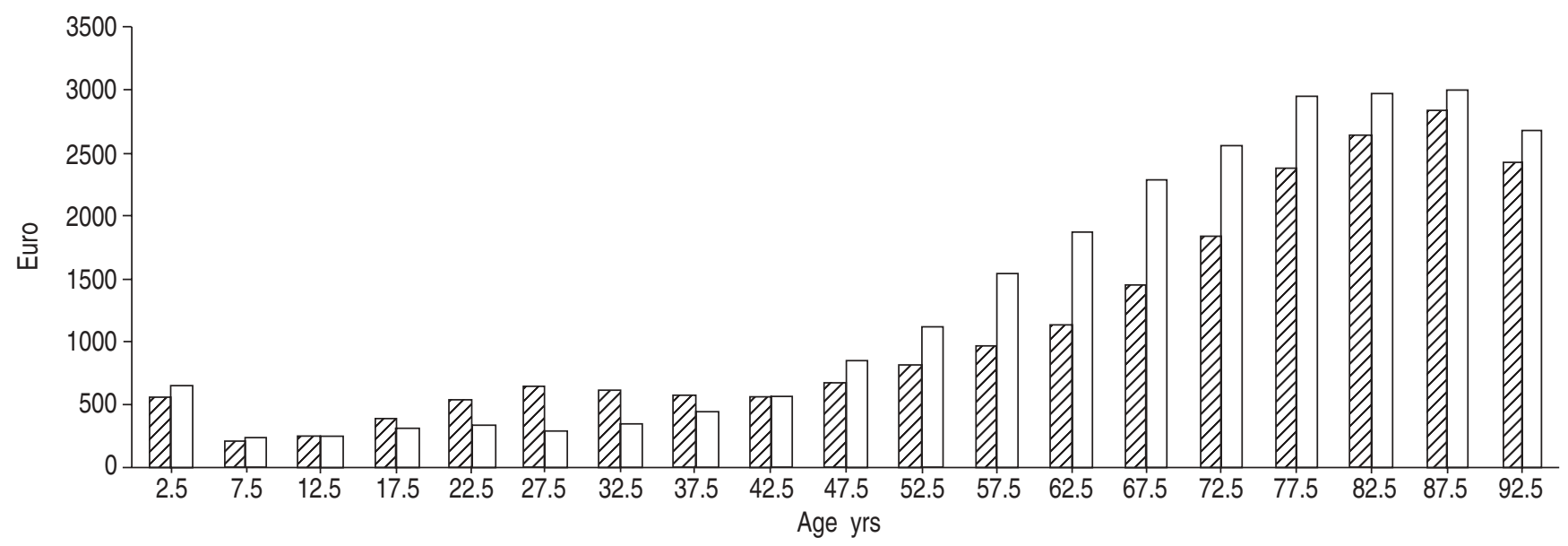

FIGURE 2. Average hospital costs of patients with asthma stratified according to age. $\mathbb{Z}:$ female; $\square:$ male.

$\sim 9.1 \%$. The bulk of medication cost of $€ 5,831.3$ million is caused by medication that is not primarily asthma related. However, asthmatics suffer more often from pulmonary

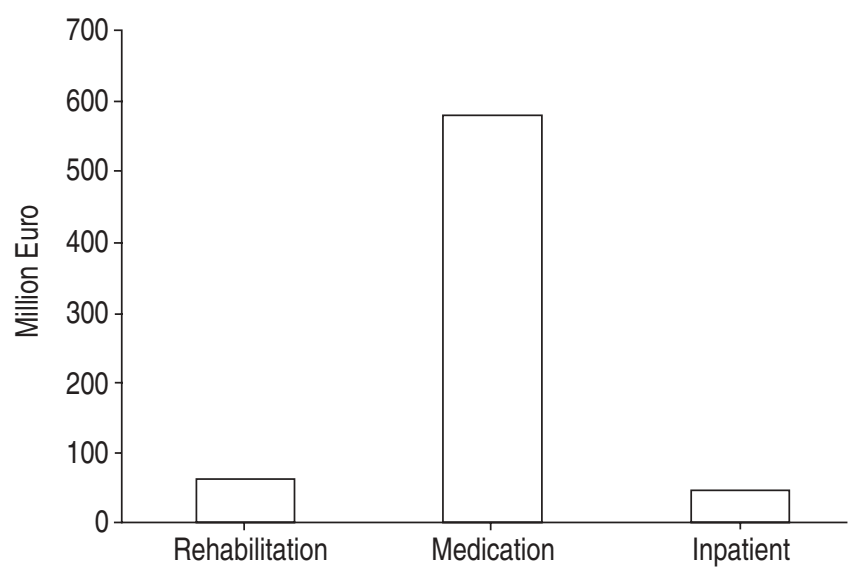

FIGURE 3. Direct costs of asthma in Germany in 1999.

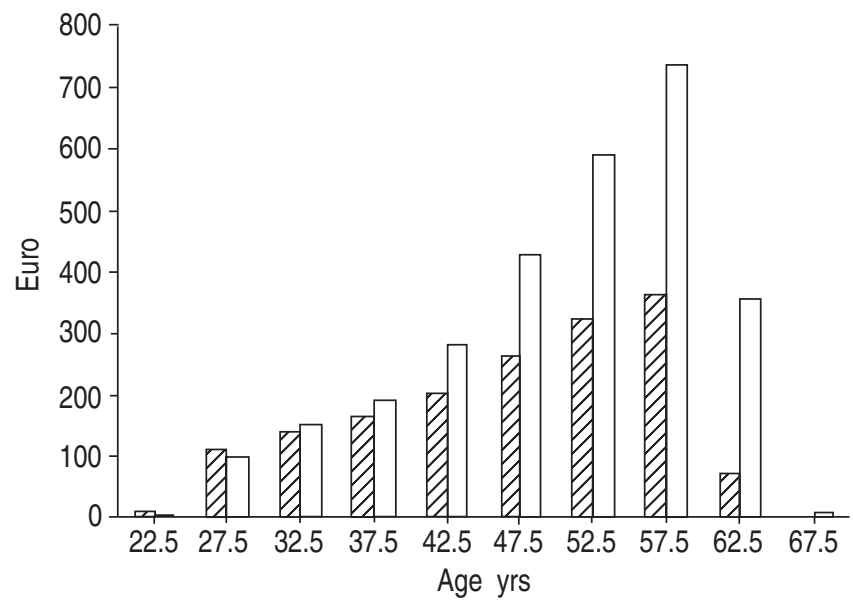

FIGURE 4. Average sick benefit payment of patients with asthma stratified according to age and sex. $\mathbb{Z}$ : female; $\square$ : male. infections and have a higher risk of developing certain comorbidities than other patients. As this effect is hard to distinguish in praxis and diagnosis, total medication cost was more accurately taken to reflect the costs of asthmatics in comparison with nonasthmatics.

\section{Indirect costs}

Sick benefits are the major source of indirect costs for insurants with asthma. Total costs for sick benefits were calculated from sickness funds claims data stratified according to age and sex (fig. 4).

Average sick benefit payment of patients with asthma for the sample tested amounted to $€ 468$ million for females and to $€ 725.9$ million for males. Extrapolated to the whole GKV the total cost for sick benefits can be estimated at around $€ 1194.8$ million (fig. 5).

In 1999 there were 833 male and 651 female cases that retired prematurely due to asthma, on the hypothesis that males and females start their working life at aged $20 \mathrm{yrs}$ and retire at aged 65 or 62 yrs, respectively. This amounts to 9,831 lost years of productivity for males and 7,081 lost years of productivity for females. Average gross income per month was around $€ 3,300$

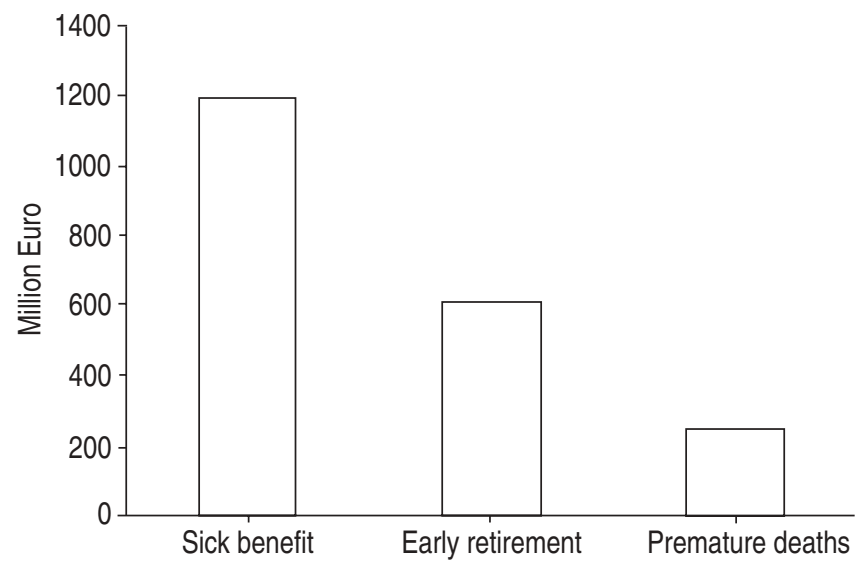

FIGURE 5. Indirect costs of asthma in Germany in 1999 
for males and $€ 2,600$ for females per month in 1999. This results in costs of $€ 39,600$ per year of lost productivity for males and $€ 31,200$ per year for females. Multiplied with the lost years of productivity overall costs amounted to $€ 610.2$ million in 1999 for both sexes in the working age population.

The Federal Statistics Office lists 444 cases of death in the working population in males and 297 cases in females in 1999 [22]. This amounts to 4,496 yrs of lost productivity for working age males and 2,542 yrs for females. Data was corrected to the age of 62 yrs for females. Multiplied with the average gross income of insurants in the year 1999, total costs for lost productivity due to premature death for both sexes amount to $€ 244.5$ million.

\section{DISCUSSION}

This study estimates the prevalence and cost of illness for asthma in Germany using sickness funds' claims data augmented by national statistics. The database comprises all types of sickness funds, except one, and is to the authors' best knowledge the only study so far evaluating data from more than one sickness fund and more than one type of fund. The main results of the study are confirmed by other studies that evaluated data from only the single largest insurance type in the GKV, the Allgemeine Ortskrankenkasse (AOK) and surveys [28, 29].

The overall prevalence of asthma in adults in the current study was $6.34 \%$. So far, the overall prevalence in Germany was estimated mainly on the basis of random samples. A survey comprising East and West German inhabitants, the German National Health Interview and Examination Survey of 1998, found overall prevalence of asthma based on a patient questionnaire and physicians interview of patients to be $5.6 \%$ with a East-West difference of $2 \%$ (3.7\% to $6.1 \%$ respectively) [13]. An East-West difference with higher prevalence in the West was also observed in a patient questionnaire by PEARCE et al. [3] comparing asthma prevalence in the ISAAC study and the ECRHS. RICHTER et al. [30] found in the same study that the prevalence of bronchial hyperresponsiveness increased in East Germany and thus could suggest the expected converging tendency between East and West Germany [3, 30].

International studies show a consistent trend towards higher prevalence in asthma, especially in childhood. This trend is thought to be real and not caused by changes in coding or diagnosis [31]. In concordance with other studies the current authors found a high prevalence in young children aged 29 yrs, with a peak around the third to fifth year of life [32-34]. At that age a high prevalence of symptoms does not necessarily correlate with a similar high prevalence rate of the diagnosis "asthma" [31, 34, 35]. The lower prevalence in diagnosis could be explained by research methods. The concordant rates of symptoms in the study of WEISHOFFHOUBEN et al. [34], along with the prevalence rates from the current study, suggest that children are treated, but the diagnosis of asthma is not yet established at a very young age [34].

Compared to previous studies the current study comprises both East and West Germany. Considering all studies done there is no consistent trend for an increase of asthma prevalence or bronchial hyperresponsiveness [36, 37]. Yet the overall prevalence of asthma in adults in the current study is slightly higher than comparable samples [13]. The slightly higher prevalence in the current study could be due to the tracer medication used. Although inhaled corticosteroids are first line drugs recommended in guidelines for the treatment of asthma they are also predictive of COPD, as in an earlier study in eight German practices [26]. This could lead to a misclassification of COPD patients as asthmatics for patients that had no hospital admission for asthma or COPD. This is also very likely to be the cause for the slightly higher prevalence in males versus females from age 62 yrs onwards.

Total costs for asthma in the current study amounted to $€ 2.74$ billion, which compares with a marginal increase to the total costs calculated by WeISSFLOG et al. [29] in a similar approach in 1996. Given the fact that neither the current study nor the study by WEISSFLOG et al. [29] could utilise physician costs in direct cost, total costs of illness for asthma can be estimated to be slightly higher than in the current study. Although direct costs added up to only $25.2 \%$ of the total costs, which is a slightly lower amount than that calculated by WeISSFLOG et al. [29] $(33 \%)$, other studies suggest that physician costs may run up to $22 \%$ in direct costs when considered separately. Another difference can be seen when direct costs are broken down into their components. Medication holds the highest percentage of direct costs at $83.9 \%$, whereas hospitalisation and rehabilitation only amount to $6.9 \%$ and $9.1 \%$, respectively. WEISSFLOG et al. [29] found that costs of medication amount to $55 \%$ for asthma and $63 \%$ for COPD. The higher percentage in the current study can partly be explained by the fact that the current authors identified patients via diagnosis and medications tracers. The inhaled steroids used as tracer were aligned with the diagnosis of COPD in an earlier study. The smaller proportion in hospital costs and the higher proportion in medication costs could also point to a better control of asthma in the population and presumably to a higher rate of treated patients, which would be concordant with the slight rise in prevalence. Furthermore, the difference in hospital costs can at least partly be explained by an overall trend to shorter hospital stays. Thus, the total amount of inpatient days that WeISSFLoG et al. [29] used as a basis for calculation can be expected to have declined between 1996-1999. Additionally, the figure that WeIsSFLOG et al. [29] used to calculate inpatient cases is roughly double the number that the hospital statistic shows for 1999.

Indirect costs amount to $74.8 \%$ of total costs, with sick benefit having the greatest part with $58.3 \%$. Early pensions and premature deaths amount to $29.8 \%$ and $11.9 \%$, respectively. Compared to the findings of WEISSFLOG et al. [29] this means that costs due to early retirement declined while costs for sick payment increased [29]. However, other studies also found sick benefit to account for the greatest cost factor in indirect costs $[10,28]$. As an overall trend this could manifest better care for asthmatic patients, with better control avoiding early retirement. The shift from early retirement to an increase in sick benefits could also at least partly be attributed to the possible contamination with cases of COPD as this population tended to have higher sick benefits in previous studies, or may be due to a prior under-reporting of the diagnosis of asthma for sick benefits as shown in Sweden [38]. The hypothesis that the overall care of asthmatic patients with a severe form of 
asthma has improved is also backed by the decline of total asthma related mortality from 1996 to 1999.

The comparison of studies assessing direct and indirect costs of asthma in Germany underscores important facts: the single most important cost driver of direct costs in most studies is medications. At the same time it can be observed that costs for early retirement and premature deaths, especially hospital costs, declined. It is likely that hospital costs have been overestimated so far.

This could point to better outpatient management of the disease and a shift from more severe to more moderate cases. However, given the manifest care deficits this study also shows that there is room for cost saving potential, as adequate treatment is associated with lower sick days and the cost of sick days amounts to the greatest percentage of indirect costs [39].

\section{REFERENCES}

1 Holland WW and the EC Working Group on Health Services and "Avoidable Death" European community atlas of avoidable death 1985-1989. Edition Series: Commission of the European Communities, Health Services Research Series No. 9; Oxford, Oxford University Press, 1997.

2 von Mutius E. The rising trends in asthma and allergic disease. Clin Exp Allergy 1998; 28: 45-49.

3 Pearce N, Sunyer J, Cheng S, et al. Comparison of asthma prevalence in the ISAAC and the ECRHS. ISAAC Steering Committee and the European Community Respiratory Health Survey. International Study of Asthma and Allergies in Childhood. Eur Respir J 2000; 16: 420-426.

4 Sunyer J, Basagana X, Burney P, Anto JM. International assessment of the internal consistency of respiratory symptoms. European Community Respiratory Health Study (ECRHS). Am J Respir Crit Care Med 2000; 162: 930-935.

5 Soriano JB, Kiri VA, Maier WC, Strachan D. Increasing prevalence of asthma in UK primary care during the 1990s. Int J Tuberc Lung Dis 2003; 7: 415-421.

6 Burr ML, Butland BK, King S, Vaughan-Williams E. Changes in asthma prevalence: two surveys 15 years apart. Arch Dis Child 1989; 64: 1452-1456.

7 Shaw RA, Crane J, O'Donnell TV, Porteous LE, Coleman ED. Increasing asthma prevalence in a rural New Zealand adolescent population: 1975-89. Arch Dis Child 1990; 65: 1319-1323.

8 Weiss KB, Sullivan SD. The economic costs of asthma: a review and conceptual model. Pharmacoeconomics 1993; 4: 14-30.

9 Robertson CF, Heycock E, Bishop J, Nolan T, Olinsky A, Phelan PD. Prevalence of asthma in Melbourne schoolchildren: changes over 26 years. BMJ 1991; 302: 1116-1118.

10 Konietzko N, Fabel H. Weißbuch Lunge - Die Lunge und ihre Erkrankungen: Zur Lage und Zukunft der Pneumologie in Deutschland [White book - Lung and bronchi Pulmonological disaese: State of the art and future of pneumology in Germany]. Stuttgart, Georg Thieme Verlag, 2000.
11 Anthracopoulos M, Karatza A, Liolios E, Triga M, Triantou K, Priftis K. Prevalence of asthma among schoolchildren in Patras, Greece: three surveys over 20 years. Thorax 2001; 56: 569-571.

12 Janson C, Chinn S, Jarvis D, Burney P. Physiciandiagnosed asthma and drug utilization in the European Community Respiratory Health Survey. Eur Respir J 1997; 10: $1795-1802$.

13 Hermann-Kunz E. Incidence of allergic diseases in East and West Germany. Gesundheitswesen 1999; 61: S100-S105.

14 Burney PG, Chinn S, Rona RJ. Has the prevalence of asthma increased in children? Evidence from the national study of health and growth 1973-86. BMJ 1990; 300: 1306-1310.

15 Ronchetti R, Indinnimeo L, Bonci E, et al. Asthma selfmanagement programmes in a population of Italian children: a multicentric study. Italian Study Group on Asthma Self-Management Programmes. Eur Respir J 1997; 10: $1248-1253$.

16 Smith DH, Malone DC, Lawson KA, Okamoto LJ, Battista C, Saunders WB. A national estimate of the economic costs of asthma. Am J Respir Crit Care Med 1997; 156: 787-793.

17 Abdulwadud O, Abramson M, Forbes A, James A, Walters EH. Evaluation of a randomised controlled trial of adult Asthma education in a hospital setting. Thorax 1999; 54: 493-500.

18 Lagerlov P, Veninga CC, Muskova M, et al. Asthma management in five European countries: doctors' knowledge, attitudes and prescribing behaviour. Drug Education Project (DEP) group. Eur Respir J 2000; 15: 25-29.

19 Suh D, Shin S, Voytovich R, Zimmerman A. Economic impact of an asthma education programme on medical care utilisation. Dis Manage Outcomes 2000; 3: 159-170.

20 Piecoro LT, Potoski M, Talbert JC, Doherty DE. Asthma prevalence, cost, and adherence with expert guidelines on the utilization of health care services and costs in a state Medicaid population. Health Serv Res 2001; 36: 357-371.

21 Wahlström R, Lagerlov P, Lundborg CS, et al. Variations in general practitioners' views of Asthma management in four European countries. Soc Sci Med 2001; 53: 507518.

22 Department of statistics, Germany. www.destatis.de/themen/d/thm_gesundheit.htm. Date updated: 14 March 2004; date accessed: 14 March 2004.

23 Verband Deutscher Rentenvericherugträger [Association of German Pension Funds]. www.vdr.de, Date updated: March 2004; date accessed: March 2004.

24 Drummond M, O'Brien B, Stoddart G, Torrance G. Costbenefit analysis. In: Drummond M, OBrien B, Stoddart G, Torrance G, eds. Methods for the Economic Evaluation of Health Care Programmes. 2nd Edn. Oxford, Oxford University Press, 1997: 205-231.

25 Barnes PJ, Jonsson B, Klim JB. The costs of asthma. Eur Respir J 1996; 9: 636-642.

26 Himmel W, Hummers-Pradier E, Schumann $\mathrm{H}$, Kochen MM. The predictive value of asthma medications to identify individuals with asthma- a study in German general practices. Br J Gen Pract 2001; 51: 879-883. 
27 Simoes E, Freund JF, Grzeschiuchna CM, Schwoerer P, Schmahl FW. Quality of statutory inpatient database before introducing DRGs. Gesundheitswesen 2002; 64: 521-526.

28 Nowak D, Volmer T, Wettengel R. Bronchial asthma- a cost of illness analysis. Pneumologie 1996; 50: 364-371.

29 Weissflog D, Matthys H, Virchow JC Jr. Epidemiology and costs of bronchial asthma and chronic bronchitis in Germany. Dtsch Med Wochenschr 2001; 126: 803-808.

30 Richter K, Heinrich J, Jorres RA, Magnussen $\mathrm{H}$, Wichmann HE. Trends in bronchial hyperresponsiveness, respiratory symptoms and lung function among adults: West and East Germany. INGA Study Group. Indoor Factors and Genetics in Asthma. Respir Med 2000; 94: 668-677.

31 Maziak W, Behrens T, Brasky TM, et al. Are asthma and allergies in children and adolescents increasing? Results from ISAAC phase I and phase III surveys in Munster, Germany. Allergy 2003; 58: 572-579.

32 Haby MM, Peat JK, Marks GB, Woolcock AJ, Leeder SR. Asthma in preschool children: prevalence and risk factors. Thorax 2001; 56: 589-595.
33 Barbato A, Panizzolo C, Biserna L, et al. Asthma prevalence and drug prescription in asthmatic children. Allerg Immunol (Paris) 2003; 35: 47-51.

34 Weishoff-Houben M, Derkx R, Feldhoff $\mathrm{KH}$, et al. Interreg II-European regional study of chronic respiratory tract diseases in children in the Germany-Netherlands border zone. Gesundheitswesen 2001; 63: 166-169.

35 Nickel R, Lau S, Niggemann B, et al. Messages from the German Multicentre Allergy Study. Pediatr Allergy Immunol 2002; 13: 7-10.

36 Frye C, Heinrich J, Wjst M, Wichmann HE. Increasing prevalence of bronchial hyperresponsiveness in three selected areas in East Germany. Bitterfeld Study Group. Eur Respir J 2001; 18: 451-458.

37 Leupold $\mathrm{W}$. The incidence of asthma and allergic diseases in children in the united Germany. Dtsch Med Wochenschr 1993; 118: 686-687.

38 Nathel L, Malmberg P, Lundback B, Nygren A. Is asthma underestimated as a cause of sick leave? Respir Med 2000; 94: 977-982.

39 Kercsmar CM, Myers TR. Clinical pathways in treatment of asthma. Curr Opin Allergy Clin Immunol 2002; 2: 183187. 